\title{
COMPORTAMENTO INFOCOMUNICACIONAL: UM DIAGNÓSTICO ENTRE ESTUDANTES PARA A PROMOÇÃO DE COMPETÊNCIAS INFOCOMUNICACIONAIS
}

\author{
INFOCOMMUNICATION BEHAVIOR: A DIAGNOSIS \\ BETWEEN STUDENTS FOR THE PROMOTION OF \\ INFOCOMMUNICATION COMPETENCES
}

\author{
Gleise da Silva Brandãoa \\ Jaires Oliveira Santos ${ }^{b}$ \\ Jussara Borges ${ }^{c}$
}

\begin{abstract}
RESUMO
Introdução: O comportamento infocomunicacional reflete a forma como as pessoas relacionam-se com o conteúdo (a informação) e com outras pessoas (a comunicação). Objetivo: Pretende-se, neste artigo, conhecer o comportamento infocomunicacional de um grupo como diagnóstico necessário antes de ofertar um curso de competências infocomunicacionais. Metodologia: Nesse sentido, adota-se a abordagem quantiqualitativa, na perspectiva de quantificar os dados, mas também oferecer interpretações e inferências qualitativas. A coleta de dados deu-se a partir da aplicação de um questionário, respondido por 15 estudantes de Arquivologia e Biblioteconomia sobre seu comportamento perante a informação e a comunicação. Portanto, trata-se da percepção dos próprios estudantes a partir de questões de múltipla escolha. Resultados: Os resultados indicaram que os sujeitos investigados buscam informações sobre temas gerais para sanar necessidades corriqueiras, utilizando estratégias de busca; confrontam e avaliam as informações, especialmente quanto à atualização e ao contexto para que seja possível identificar manipulação, distinguindo, sobretudo, fatos de opiniões. No aspecto comunicacional, utilizam aplicativos de mensagens instantâneas e correio eletrônico como ferramentas de

a Doutoranda em Ciência da Informação pelo Programa de Pós-Graduação em Ciência da Informação da Universidade Federal da Bahia (PPGCI/UFBA). Docente do Departamento de Fundamentos e Processos Informacionais da Universidade Federal da Bahia (DFPI/UFBA). Email: gleise.brandao@ufba.br.

b Doutoranda em Ciência da Informação pelo Programa de Pós-Graduação em Ciência da Informação da Universidade Federal da Bahia (PPGCI/UFBA). Docente do Departamento de Fundamentos e Processos Informacionais da Universidade Federal da Bahia (DFPI/UFBA). Email: jaires.oliveira@ufba.br.

c Doutora em Comunicação e Cultura Contemporâneas pela Universidade Federal da Bahia. Docente na Faculdade de Biblioteconomia e Comunicação (Fabico) da Universidade Federal do Rio Grande do Sul (UFRGS) e nos Programas de Pós-Graduação em Ciência da Informação da Universidade Federal da Bahia (PPGCI/UFBA) e da Universidade Federal do Rio Grande do Sul (PPGCIN/UFRGS). E-mail: jussara.borges@ufrgs.br.
\end{abstract}


comunicação e também as redes sociais para se manterem informados e compartilhar conteúdos. Preocupam-se com a confiabilidade da informação, porém possuem limitações relacionadas à interação efetiva nesses espaços. Conclusões: Conclui-se que o delineamento de um perfil infocomunicacional é determinante para o sucesso de ações e estratégias que favoreçam a promoção de competências infocomunicacionais.

Descritores: Comportamento infocomunicacional. Competências infocomunicacionais. Comportamento informacional. Comportamento comunicacional.

\section{INTRODUÇÃO}

De acordo com o Comitê Gestor da Internet (CGI.br, 2019), 76\% dos brasileiros acessam a internet todos os dias. O que essas pessoas acessam é informação em seus diferentes formatos (música, vídeos, textos etc.). Além desse acesso a conteúdos, 92\% utilizam a plataforma para comunicação (mensagens instantâneas, redes sociais, conversas por chamada de áudio e vídeo, correio eletrônico, etc). A vida contemporânea é, portanto, abundante em atividades de informação e comunicação. Estima-se que cerca de 9 horas do tempo acordado de um indivíduo comum é consumido no processamento de informações e comunicação para atender às demandas de trabalho, estudo, lazer e responsabilidades diversas. Mesmo aqueles ditos excluídos digitais são impactados pela cultura de informação vigente, na medida em que têm de retirar seus exames de laboratório pela internet, acessar documentos em portais de governo eletrônico e pagar contas online, para citar alguns exemplos.

Para levar a cabo tais atividades, as pessoas mobilizam competências em informação e em comunicação, aqui chamadas infocomunicacionais. As competências infocomunicacionais podem ser caracterizadas como a convergência de conhecimentos, habilidades e atitudes que cada um põe em ação para localizar e usar a informação necessária e interagir com outras pessoas. Essa qualidade de competências expressa-se no comportamento infocomunicacional, ou seja, na forma como as pessoas relacionam-se com o conteúdo (a informação) e com outras pessoas (a comunicação).

Este artigo identifica o comportamento infocomunicacional de um grupo de estudantes de Arquivologia e Biblioteconomia. Esses estudantes se 
matricularam em um curso de promoção de competências infocomunicacionais, realizado entre maio e setembro de 2018, na modalidade semi-presencial.

O fundamento teórico-metodológico do trabalho advém de estudos sobre comportamento informacional (information behavior) e indicadores de avaliação de competências infocomunicacionais (BORGES, 2018). A abordagem é quanti-qualitativa, na perspectiva de quantificar os dados, mas também oferecer interpretações e inferências qualitativas. Esses dados foram obtidos através de um questionário respondido por 15 estudantes de Arquivologia e Biblioteconomia sobre seu comportamento diante da informação e da comunicação. Portanto, trata-se da percepção dos próprios estudantes a partir de questões de múltipla escolha.

Assim, este diagnóstico é resultante da tentativa de se ter um ponto de partida para o planejamento e desenvolvimento de ações para a promoção das competências infocomunicacionais, de forma que tais ações pudessem ser personalizadas e direcionadas ao público a que se destina.

\section{COMPORTAMENTO INFOCOMUNICACIONAL}

Esta seção não pretende discutir a inter-relação entre competência em informação e comportamento informacional, para o que já existe alguma literatura (SHENTON, HAY-GIBSON, 2011; FURTADO, ALCARÁ, 2015; OTTONICAR; NASCIMENTO; BASSETO, 2018), mas demonstrar a relevância do conhecimento do comportamento informacional em projetos que pretendem a promoção dessas competências.

Um projeto dessa natureza, que entenda as competências como uma prática sócio-técnica não se constrói sem o conhecimento do comportamento do grupo partícipe. Primeiro é preciso reconhecer que as pessoas desenvolvem ao longo da vida formas que, com algum sucesso, suprem suas necessidades informacionais. Para prover acesso, assimilam artefatos e sistemas de informação que estejam acessíveis - física e cognitivamente - como rádio, televisão, bibliotecas, internet etc. Em seguida, constroem sentido para a informação acessada através da interação social, o que, segundo Tuominen, 
Savolainen e Talja (2005), é uma prática social amparada no diálogo e no debate.

Negar ou ignorar essas práticas impondo um pacote fechado com o que deve ser "aprendido", além de ser um desprezo pelo conhecimento préexistente do grupo em foco, é um desperdício de oportunidades de aprendizagem. É importante reconhecer que as pessoas trazem uma bagagem de práticas informacionais que conformam o seu comportamento.

De acordo com Berrío-Zapata et al. (2016) até as décadas finais do século $\mathrm{XX}$, os estudos costumavam ver o usuário como extensão do sistema de informação; e qualquer comportamento autônomo, fora do padrão previsto de uso do sistema, era considerado impróprio, demandando treinamento para atender aos padrões técnicos do sistema. "O usuário se reduzia a um receptor passivo a ser iluminado, que devia enquadrar-se nos sistemas centralizados, hegemônicos e racionalistas." (BERRÍO-ZAPATA et al., 2016, p. 137, tradução nossa).

A perspectiva das competências infocomunicacionais vai de encontro a esta visão, já que o conceito envolve o desenvolvimento de atitudes perante a informação, seus sistemas e técnicas. Como avaliam Ottonicar, Nascimento e Basseto (2018, p. 21) "A competência em informação está relacionada com o comportamento informacional à medida que considera as atitudes das pessoas como parte de seu conceito.". Assim, a proposta não é ensinar as pessoas a lidar com este ou aquele sistema, mas empoderá-las para desenvolver conhecimentos, habilidades e atitudes para fazer escolhas conscientes e aderentes às suas necessidades e contexto sócio-técnico.

Com a popularização da internet e suas ferramentas descentralizadoras de acesso e produção de conteúdos, os estudos de comportamento informacional voltaram-se ao cidadão comum, porque passa a ser crítico entender os padrões de decisão e ação desses sujeitos para poder captar sua atenção e, quem sabe, modelar sua vontade (BERRíO-ZAPATA et al., 2016). Também para Gasque e Costa (2010, p. 30) - que investigaram a evolução teórico-metodológica dos estudos sobre comportamento informacional -, a partir dos anos 2000 se percebe que o conceito se abre para abranger "toda a 
gama de estudos relacionados com o usuário e a informação", incluindo estudos de necessidades informacionais, e de como as pessoas buscam, gerenciam, disseminam e usam informação, tanto de forma proposital, quanto passivamente.

O centro de análise do comportamento informacional desloca-se para o sujeito, suas necessidades cotidianas, os processos de construção de significado e seu contexto. As pesquisas diversificam os grupos estudados e adotam abordagem multifacetada, reconhecendo que os indivíduos estão constantemente buscando e usando informações (GASQUE; COSTA, 2010):

\begin{abstract}
A partir desta perspectiva, o comportamento informacional é produto e resultado da negociação social de sentido, atividade humana que está mediada pela linguagem. Neste contexto de diálogo e negociação, a Ciência da Informação estende seus estudos para incluir elementos sociocognitivos ocultos atrás das atividades e estruturas simbólicas da informação e suas tecnologias (BERRíO-ZAPATA et al., 2016, p. 140, tradução nossa).
\end{abstract}

Frequentemente os estudos de comportamento informacional focam em três dimensões: o reconhecimento de uma necessidade informacional por parte de um indivíduo, a busca e a aquisição de material em resposta a essa necessidade e o uso do que foi localizado para responder à situação que estimulou a ação tomada (SHENTON; HAY-GIBSON, 2011). Essas dimensões claramente coincidem com os principais componentes da competência em informação: perceber uma necessidade de informação, saber onde buscá-la, aplicar critérios de validação do conteúdo e usá-la para responder à motivação de busca inicial. Furtado e Alcará (2015), que fizeram uma análise das características dos modelos de comportamento informacional, observaram que o grau de complexidade das competências exigidas evolui de forma gradativa conforme o indivíduo avança no processo de busca e uso da informação. Assim, nas etapas finais, que envolvem verificação e aplicação, há necessidade de maior reflexão e autonomia de aprendizagem, considerando a mutabilidade do universo informacional.

Sobre o aspecto comunicacional, é interessante notar que ele já aparece no conceito de comportamento informacional: 
Information Behavior is the totality of human behavior in relation to sources and channels of information, including both active and passive information seeking, and information use. Thus, it includes faceto-face communication with others, as well as the passive reception of information as in, for example, watching TV advertisements, without any intention to act on the information given (WILSON, 2000, p. 49, grifos nossos).

De fato, informação e comunicação encontram pontos de interseção, porque enquanto a comunicação não existe sem conteúdo - a informação - esta necessita da relação estabelecida pela comunicação para a construção de sentido: "[...] enquanto a informação é da ordem do conteúdo, a comunicação é da ordem da relação." (PASSARELI et al, 2014, p. 102). Tuominen, Savolainen e Talja, em 2005 já chamavam a atenção para o fato de que muitos padrões de competência em informação as consideravam como atributo individual, sem ter em conta o aspecto ambiental, ou seja, como os indivíduos desenvolvem competências pela interação com outros e com os artefatos técnicos de seu ambiente informacional.

Embora o conceito de competências infocomunicacionais não seja 0 foco deste trabalho, é importante elucidar que o curso de competências que se quer promover está amparado numa base conceitual (BORGES; BRANDÃO, 2017; BORGES, 2018), que pode ser sumarizada no Quadro 1

\section{Quadro 1 - Categorias de promoção das competências infocomunicacionais}

\begin{tabular}{|c|c|}
\hline Tipo de competência & Categoria \\
\hline \multirow{3}{*}{$\begin{array}{c}\text { Competência em } \\
\text { informação }\end{array}$} & Perceber uma necessidade de informação \\
\cline { 2 - 2 } & Buscar em fontes de informação \\
\cline { 2 - 2 } & Avaliar a informação \\
\cline { 2 - 2 } $\begin{array}{c}\text { Competência em } \\
\text { comunicação }\end{array}$ & Usar a informação \\
\cline { 2 - 2 } & Estabelecer comunicação \\
\cline { 2 - 2 } & Compartilhar conteúdos \\
\cline { 2 - 2 } & Desenvolver laços sociais \\
\cline { 2 - 2 } & Atuar colaborativamente \\
\hline
\end{tabular}

Fonte: Elaborado pelas autoras, 2019

Em síntese, conhecer o comportamento infocomunicacional do grupo em que se pretende promover novas competências pode ser útil em, pelo menos três âmbitos: (a) customizar o curso ou programa àquilo que de fato pode representar um adicional ou melhoria ao comportamento perante a informação 
e a comunicação; (b) aproveitar os conhecimentos do grupo para avançar no conteúdo, método ou estratégias de ensino-aprendizagem; (c) obter o engajamento de todos os envolvidos, uma vez que mais que alunos, clientes ou usuários, eles são sujeitos ativos e corresponsáveis pela aprendizagem do grupo.

\section{PROCEDIMENTOS METODÓLOGICOS}

Em atenção ao objetivo que move este estudo, aplicou-se um questionário online, através da plataforma Moodle, com 15 estudantes dos cursos presenciais de Arquivologia e Biblioteconomia da Universidade Federal da Bahia (UFBA), composto por questões objetivas sobre seus comportamentos perante a informação e a comunicação, aplicado entre os dias 06 e 26 de junho de 2018.

Esses estudantes são uma amostra - por adesão espontânea - dentre os 50 que se matricularam no curso de extensão em Competências InfoComunicacionais, oferecido em 2018, no formato EaD, pelo Grupo de Estudos em Políticas de Informação, Comunicação e Cultura (Gepicc) da UFBA. No que diz respeito à sua caracterização, destacamos que os 15 estudantes cursavam do primeiro ao terceiro semestre dos cursos presenciais de Arquivologia (7) e Biblioteconomia (8) da UFBA, sendo 11 do gênero feminino e 4 do gênero masculino, cuja faixa etária corresponde entre 17 e 54 anos.

As questões que compõem o instrumento de coleta de dados foram formuladas com o intuito de captar o comportamento dos respondentes em situações vivenciadas (como o comportamento em um debate conflituoso) ou muito próximas da sua realidade, de modo que as respostas refletissem o comportamento real em detrimento da opinião ou conhecimento sobre a temática.

As categorias de análise quanto ao comportamento informacional são: percepção da necessidade de informação, comportamento de busca em fontes de informação, critérios empregados na avaliação da informação, opções de 
organização e uso da informação. Já o segundo grupo se refere ao comportamento comunicacional e conta com as seguintes categorias: como estabelecer comunicação, escolhas quanto ao compartilhamento de conteúdos, meios de desenvolvimento de laços sociais, colaboração em rede e critérios de avaliação da comunicação. Tais categorias foram definidas com base no aporte teórico da área e de indicadores de verificação de competências infocomunicacionais (BORGES, 2018) e encontram-se sinalizadas em negrito no corpo do texto, na medida em que forem abordadas. Vale lembrar que a perspectiva deste estudo é compreender o comportamento infocomunicacional dos sujeitos mais que prescrever competências adequadas.

\section{APRESENTAÇÃO DOS DADOS E DISCUSSÃO DOS RESULTADOS}

Para facilitar a análise dos dados, foi preciso criar categorias de análise atreladas aos grupos de tipos de comportamentos analisados, quais sejam: comportamento informacional e comportamento comunicacional, conforme apresentado no Quadro 1.

\subsection{COMPORTAMENTO INFORMACIONAL}

No que diz respeito ao comportamento informacional, a primeira categoria a ser analisada é a necessidade de informação. Esta categoria corresponde ao ato de perceber que se precisa de informação para atender a determinada necessidade, solucionar problemas ou tomar decisões. Nesse sentido, os estudantes foram questionados sobre quais atividades acreditavam necessitar de informações para realizar. A partir das respostas foi possível identificar as principais necessidades informacionais dos estudantes como mostra o Gráfico 1. 


\section{Gráfico 1 - Necessidades informacionais dos estudantes}

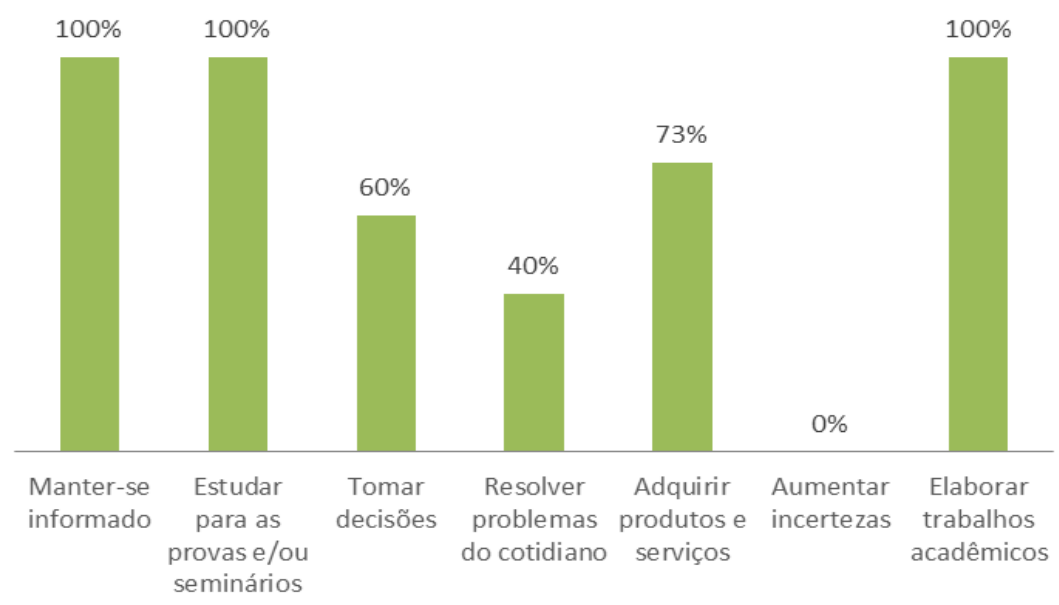

Fonte: Elaborado a partir dos dados da pesquisa (2019).

De acordo com o Gráfico 1, observa-se que dentre as principais necessidades de informação elencadas pelos estudantes estão: manter-se informado em temas gerais, estudar para as provas e/ou seminários e elaborar trabalhos acadêmicos; estas necessidades foram indicadas pela totalidade dos respondentes. Em seguida, são mencionadas outras necessidades como adquirir produtos e serviços (73\%) e tomar decisões (60\%). Apenas $40 \%$ dos estudantes acreditam que precisam buscar informações para resolver problemas do cotidiano. O que mostra que, em geral, os estudantes têm consciência de que precisam buscar informações para suprir boa parte de suas necessidades, no entanto pode-se inferir a partir dos resultados que para resolver os problemas do cotidiano estes estudantes utilizam apenas 0 conhecimento prévio.

As necessidades de informação geralmente surgem em decorrência de aspectos relacionados às atividades profissionais, mas há forte influência também dos fatores pessoais. Silveira e Oddone (2007, p. 120) asseveram que "as necessidades informacionais apresentam características mais gerais quando analisadas por grupos de usuários, uma vez que as particularidades e o contexto de cada grupo podem determinar certo padrão". Assim, como se observa no comportamento informacional do grupo de estudantes, as principais motivações estão relacionadas a esta etapa da vida. 
Ainda sobre a necessidade informacional dos estudantes, para melhor compreender o comportamento informacional quando colocados em uma situação que demandava a busca por novas informações, a seguinte situação foi proposta: Suponhamos que você precisou fazer uma viagem a trabalho para uma cidade desconhecida e precisou verificar aspectos como transporte, hospedagem, alimentação, etc. O que você faria nessa situação para obter as informações?

Os dados mostram que cerca de $80 \%$ dos estudantes afirmaram que buscariam informações na internet, enquanto que $20 \%$ optou por pedir a opinião de colegas, amigos ou familiares. Outras possibilidades como considerar as primeiras opções oferecidas por um operador de busca, levar em consideração os conhecimentos que já tem, pedir informações para desconhecidos e explorar a cidade não foram indicadas como opções.

Deste modo, percebe-se um comportamento informacional altamente focado em recursos on-line. As fontes de informações, portanto, para serem consideradas, precisam estar disponíveis e facilmente acessíveis na internet. Isso repercute tanto para os serviços de informação oferecidos por bibliotecas e arquivos quanto para o caso específico deste estudo, ou seja, aos estudantes do curso devem ser oferecidas múltiplas fontes de informação - inclusive as analógicas - mas é inegável que seu comportamento informacional dirige-se ao digital. Nessa perspectiva, Santos e Barreira (2019) apresentam reflexões que reforçam essa questão, dizendo que as unidades informacionais precisam estar presentes nesses espaços interativos, em que as novas gerações passam a maior parte do tempo, inclusive usando-as para resolver situações pontuais de suas vidas.

Outro aspecto interessante a ser analisado é a valorização da opinião de colegas, amigos ou familiares em detrimento do ato de pedir informações para desconhecidos. Isso coloca em questão o aspecto da avaliação da informação, a confiabilidade atribuída à informação a partir dos laços sociais desenvolvidos entre os indivíduos. O desenvolvimento de laços sociais é um aspecto fortemente estudado no contexto da competência em comunicação, assim este pode ser considerado um exemplo que deixa em evidência a relação bilateral 
das competências infocomunicacionais.

A segunda categoria a ser analisada neste grupo é a busca de informações. A busca informacional consiste "na tentativa intencional de encontrar informação como consequência da necessidade de satisfazer um objetivo" (SILVEIRA; ODDONE, 2007, p.121). Nesse sentido, essa categoria refere-se às fontes de informações utilizadas, como a informação é selecionada e recuperada pelo estudante e quais as estratégias utilizadas para identificar e acessar as informações que necessita. Nesse sentido, primeiro foram elencadas as fontes de informação mais utilizadas pelos estudantes para buscar as informações.

Os resultados mostram que os estudantes tendem a utilizar de forma mais intensa os buscadores ou motores de busca (87\%), os livros e dicionários (87\%). Outras pesquisas realizadas com estudantes do curso de Arquivologia (BRANDÃO; BORGES, 2014), com arquivistas (BRANDÃO; BORGES, 2018) também indicam os motores de busca como principal ferramenta para obtenção de informações. Os artigos publicados em periódicos científicos também são destaques entre as fontes de informação mais utilizadas. Entende-se que esse uso se justifica devido à inserção desses estudantes no ambiente acadêmico. Destaca-se que em estudos com bibliotecários (SANTOS, 2015), houve também uma inclinação para o uso de periódicos e livros como fontes informacionais. No entanto, há um contraponto interessante: diferentemente dos artigos científicos, neste estudo com bibliotecários as bases de dados aparecem com menor incidência.

Há de se destacar que $60 \%$ dos estudantes informaram que utilizam as redes sociais como forma de obter informações. Isso indica que este grupo passou a explorar o potencial das redes sociais como fonte de informações. No entanto, isso demanda o uso de critérios bem definidos para avaliar as informações provenientes das redes sociais, pois há grande incidência de informações falsas.

Outras fontes indicadas pelos estudantes são os sites especializados, como agências, empresas, organismos oficiais, dentre outros (com 33\%); e os blogs com apenas $27 \%$. Ressalta-se que apesar da possibilidade informativa 
dos blogs, eles vêm decaindo como fonte de informação.

Outro aspecto a ser analisado são as estratégias utilizadas por esses estudantes para realizar o processo de busca pela informação. Assim, o Gráfico 2 mostra as opções sugeridas nesse item.

\section{Gráfico 2 - Estratégias utilizadas para buscar informações}

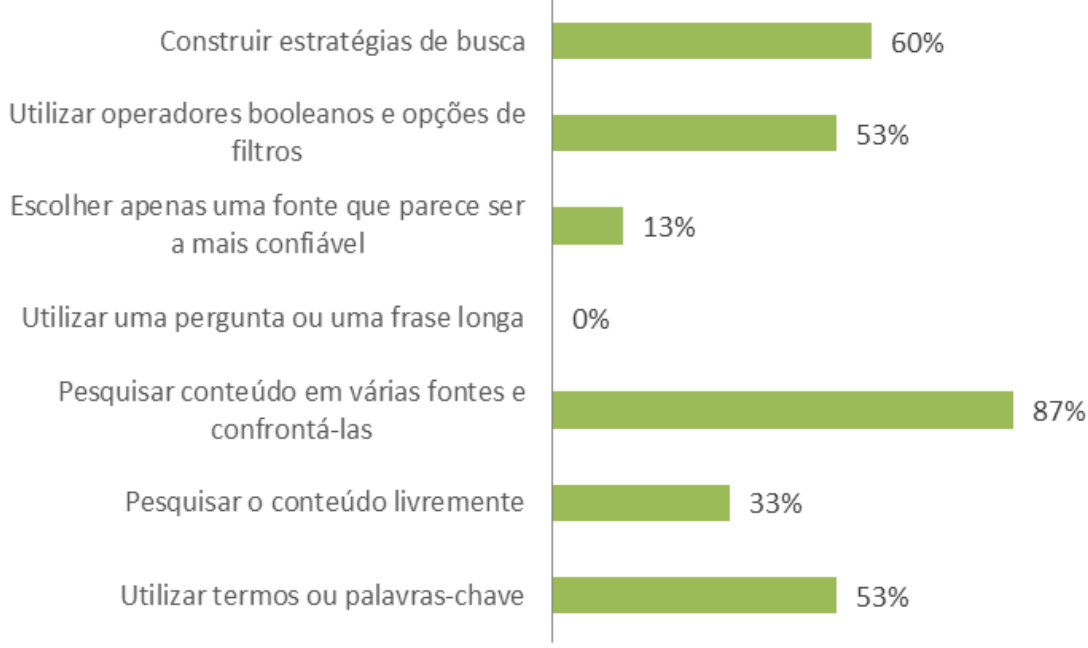

Fonte: Elaborado a partir dos dados da pesquisa (2019)

Diante dos dados apresentados, observa-se que dentre as estratégias oferecidas a mais indicada pelos estudantes foi pesquisar conteúdo em várias fontes e confrontá-las (87\%) seguida de construir estratégias de busca $(60 \%)$. Isso indica que o grupo participante já reconhece a necessidade de comparar informações a que tem acesso e não se limitar a apenas uma fonte de informação, o que poderia gerar informações incompletas, falsas e/ou manipuladas ou mesmo fora do contexto pretendido. Além disso, a construção de estratégias de busca em contraposição à alternativa "pesquisar o conteúdo livremente", que obteve $33 \%$ das respostas, sugere que os estudantes estão cientes que tais estratégias podem garantir que a busca seja mais eficiente. Outro aspecto que reforça essa afirmação decorre dos próprios dados: 53\% afirmam que utilizam operadores booleanos e opções de filtros, assim como utilizam termos ou palavras-chave; esses aspectos são reconhecidamente estratégias adequadas para refinar os resultados da busca informacional.

Assim como a busca, também é necessário verificar o posicionamento 
dos estudantes com relação à avaliação da informação, que configura a terceira categoria a ser analisada. Nesse sentido, questionou-se sobre os critérios de avaliação que os ajudam a analisar se as informações são confiáveis e pertinentes.

A questão colocada para os sujeitos que participaram da pesquisa foi "julgue os critérios de avaliação que podem te ajudar a analisar se as informações que você selecionou são confiáveis e pertinentes". Assim, listou-se critérios que correspondiam à avaliação da informação e outros que não correspondiam a mesma, como se observa na Tabela 1.

Tabela 1 - Critérios apontados pelos estudantes para avaliar a informação

\begin{tabular}{lr}
\hline $\begin{array}{l}\text { Revisar o processo de busca e incluir outras } \\
\text { fontes }\end{array}$ & $93 \%$ \\
\hline Ler e sintetizar as informações & $60 \%$ \\
\hline Verificar se a informação está atualizada & $100 \%$ \\
\hline $\begin{array}{l}\text { Analisar o contexto cultural, político, social da } \\
\text { informação }\end{array}$ & $93 \%$ \\
\hline Juntar e organizar informações dispersas & $60 \%$ \\
\hline $\begin{array}{l}\text { ldentificar se trata-se de uma opinião ou um } \\
\text { fato, ou se há tentativa de manipulação }\end{array}$ & $87 \%$ \\
\hline Utilizar termos e palavras-chave & $47 \%$ \\
\hline Elaborar um mapa conceitual & $47 \%$ \\
\hline
\end{tabular}

Fonte: Elaborado a partir dos dados da pesquisa, (2019).

Os critérios mais indicados pelos estudantes possuem vínculo direto com a avaliação da informação: verificar se a informação está atualizada $(100 \%)$, revisar o processo de busca e incluir outras fontes (93\%), analisar o contexto cultural, político, social da informação (93\%) e identificar se a informação se trata de uma opinião ou fato, ou se há tentativa de manipulação (87\%). No entanto, outros critérios são indicados de forma significativa e não estão diretamente relacionados à questão da avaliação, a citar: ler e sintetizar as informações (60\%); juntar e organizar informações dispersas $(60 \%)$; utilizar termos e palavras-chave (47\%); e elaborar um mapa conceitual $(47 \%)$. Esses critérios foram postos como opções possíveis de resposta para os estudantes no sentido de verificar se os mesmos diferem critérios de avaliação de métodos de organização e síntese da informação. 
A partir dos resultados obtidos, infere-se que os estudantes fazem alguma confusão entre os critérios de avaliação da informação e os métodos de organização e síntese, que embora tenham sua relevância, não contribuem significativamente para a avaliação de informações no que diz respeito à sua confiabilidade e pertinência.

Com relação à organização e síntese da informação, o grupo demonstrou preocupação em organizar as informações. Eles dizem ler e sintetizar as informações, juntam e organizam informações diversas, utilizam termos e palavras-chave para descrever o conteúdo. Destaca-se o uso de mapas conceituais - ferramenta para construção e inter-relação dos conceitos o que revela uma busca pela apropriação das informações, conforme defende Barreto (2009).

No que diz respeito ao uso da informação, última categoria a ser analisada no primeiro grupo que se refere ao comportamento informacional, os estudantes foram indagados sobre como costumam usar as informações selecionadas durante o processo de busca. Sendo assim, o Gráfico 3 mostra as formas de utilização da informação indicadas pelos estudantes.

Gráfico 3 - Uso da informação pelos estudantes

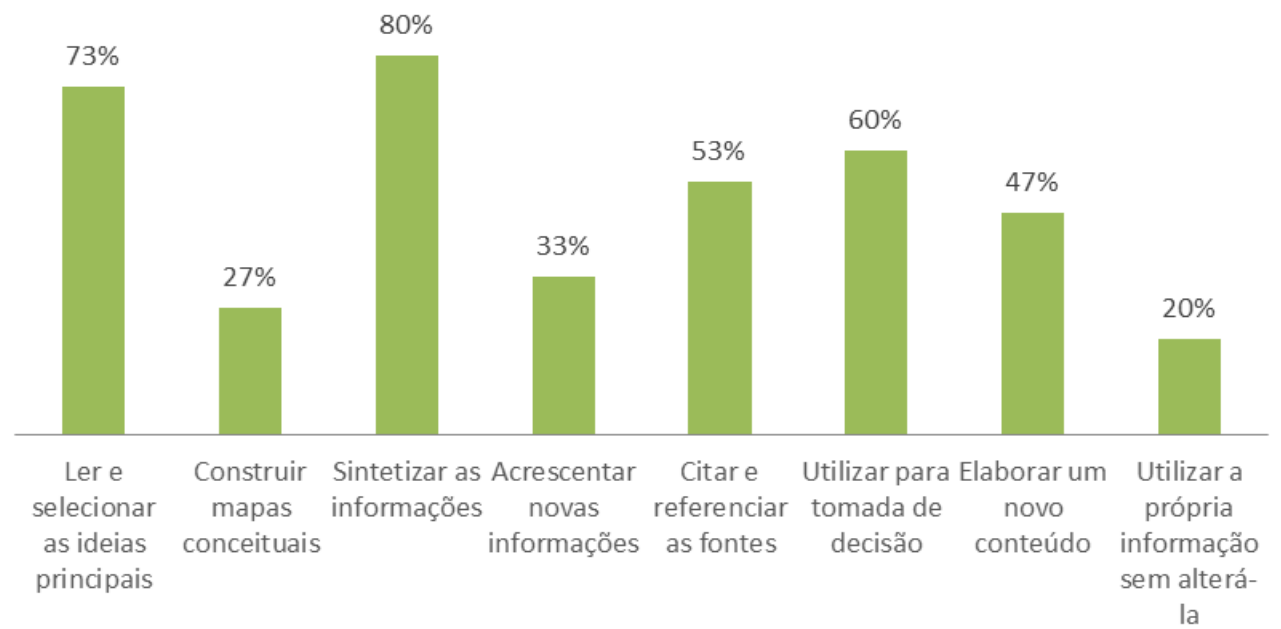

Fonte: Elaborado a partir dos dados da pesquisa (2019).

Dentre as opções disponíveis as mais apontadas foram sintetizar as informações $(80 \%)$, ler e selecionar as ideias principais (73\%), e utilizar a informação para tomada de decisão (60\%). Observa-se que opções mais 
relacionadas com a produção de conteúdo são menos indicadas pelos estudantes como, por exemplo, construir mapas conceituais (27\%) - que, embora tenha sido indicada pelos estudantes como uma ferramenta usada para organizar as informações, não é muito apontada no que diz respeito ao uso, assim ressalta-se o potencial dessa ferramenta para contribuir também na produção de conteúdo -, acrescentar novas informações (33\%) ou elaborar um novo conteúdo $(47 \%)$. Isso demonstra um comportamento mais inclinado ao consumo de conteúdos se comparado à produção.

A produção de conteúdo é aspecto importante dentro do escopo da competência em informação, porque estabelece uma relação direta com a apropriação da informação que é condição sine qua non para que o indivíduo possa transformar a informação em conhecimento. Para Barreto (2009) é a apropriação da informação que permite ao usuário modificar as suas condições de entendimento e conhecimento que o leva a sair da condição de apenas receptor para tornar-se também um produtor.

Desta forma, tendo sido analisadas as categorias correspondentes ao primeiro grupo passa-se para a análise das categorias que correspondem ao comportamento comunicacional.

\subsection{COMPORTAMENTO COMUNICACIONAL}

As categorias que compõem o segundo grupo são: como estabelecer comunicação, escolhas quanto ao compartilhamento de conteúdos, meios de desenvolvimento de laços sociais, colaboração em rede e critérios de avaliação da comunicação. Assim, o estudo deste grupo parte inicialmente da análise dos mecanismos e ferramentas de comunicação comumente utilizados pelos estudantes na Internet, questão relacionada à categoria estabelecer comunicação.

Os mecanismos e/ou ferramentas para fins de comunicação mais utilizados pelos estudantes participantes da pesquisa são os aplicativos de mensagem instantânea $(93 \%)$, sites ou redes profissionais $(80 \%)$, correio eletrônico $(80 \%)$ e redes sociais online $(73 \%)$. Por outro lado, ferramentas e/ou 
mecanismos como fóruns, listas de discussão (33\%), blogs (33\%) e wikis (13\%) são pouco indicadas pelos estudantes.

Também buscou-se verificar o comportamento dos estudantes ao estabelecer comunicação. De acordo com os resultados, os estudantes mostram-se preocupados em serem objetivos e concisos (80\%) e saber se 0 conteúdo foi devidamente entendido pelo interlocutor (73\%), requisito básico para que se estabeleça um processo comunicativo. Além disso, há grande interesse na utilização de recursos audiovisuais (73\%), haja vista a sua dinamicidade e aproximação ao perfil dos estudantes participantes.

O uso de mecanismos e/ou ferramentas de comunicação também coloca em questão outro aspecto que é o compartilhamento de informação. Com relação a essa categoria de análise foi colocada uma situação-problema para revelar o comportamento do estudante, a saber: se você encontra um artigo que pode ser útil a um amigo que está em outra universidade, qual canal ou ferramenta lhe parece mais adequado para transmitir a mensagem?

A partir dos resultados obtidos, observa-se que os estudantes se mostraram divididos entre duas opções: Enviar um whatsapp comentando (53\%) ou baixar o arquivo e enviá-lo via correio eletrônico (47\%). Observa-se que mais uma vez há uma preferência por ferramentas que oferecem uma comunicação mais rápida em consonância com o que demonstra os dados que tratam sobre os mecanismos e ferramentas de comunicação mais utilizadas.

Contudo, para além das ferramentas e/ou mecanismos utilizados no compartilhamento de informação, parece que o mais relevante nesses resultados está na atitude de compartilhar uma informação com alta chance de ser útil para alguém, uma vez que ninguém escolheu a resposta "não fazer nada".

Os estudantes tampouco escolheram o Facebook como canal de comunicação dessa informação especializada, então há que se questionar sobre a forma pela qual as informações estão sendo compartilhadas pelos estudantes (Gráfico 4). 


\section{Gráfico 4 - Comportamento ao compartilhar informações}

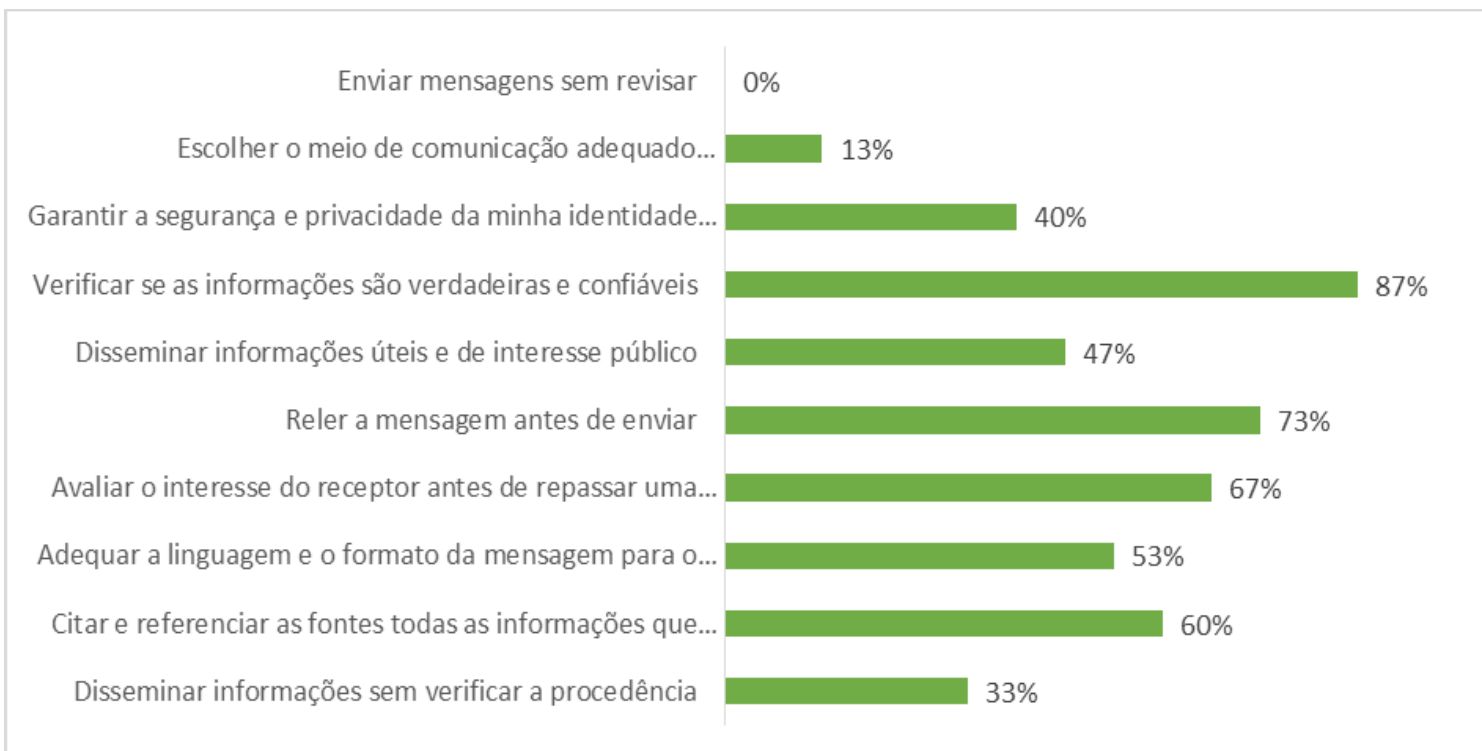

Fonte: Elaborado a partir dos dados da pesquisa (2019).

O Gráfico 4 traz dados que sugerem que os estudantes estão preocupados com a confiabilidade e fidedignidade das informações que compartilham (87\%), assim como afirmam reler a mensagem antes de enviar (73\%), avaliar o interesse do receptor antes de repassar uma informação (67\%) e citar e referenciar as fontes (60\%). Estes podem ser considerados requisitos básicos para o compartilhamento saudável de informações na internet, colocando-se em questão a responsabilidade do sujeito que compartilha a informação e não apenas daquele que a produz, especialmente num cenário no qual há grande proliferação de informações falsas, distorcidas ou fora do contexto. Ainda assim, 33\% dos estudantes afirmam que costumam disseminar informações sem se preocupar em verificar a sua procedência. É um número muito alto, principalmente considerando-se que são estudantes da área de Informação: a checagem da fonte é critério determinante da credibilidade da informação e deve ser verificada sempre.

Outros quesitos também precisam ser ressaltados como: adequar a mensagem e o formato da informação de acordo com o público que pretende atingir (53\%), disseminar informações úteis e de interesse do público (47\%), garantir a segurança e privacidade da identidade (40\%). Esses aspectos revelam certo interesse na customização da mensagem e adequação ao 
público que está muito relacionada com saber estabelecer comunicação e possibilita que tal comunicação seja mais eficaz e eficiente, o ajudando a atingir o objetivo pretendido.

Já no que tange ao desenvolvimento de laços sociais, terceira categoria a ser analisada no grupo do comportamento comunicacional, os estudantes foram questionados sobre suas motivações para participar de redes sociais, lembrando que em torno de $73 \%$ dos estudantes afirmaram que utilizam as redes sociais para fins comunicativos. Neste quesito, verifica-se que as principais motivações dos estudantes ao participar dessas redes são: manter-se informado sobre assuntos do seu interesse (87\%) e interagir com amigos e/ou conhecer pessoas. Um ponto positivo a ser observado é que as redes sociais têm sido utilizadas como meio de obtenção de informações, haja vista que a motivação para manter-se atualizado sobre assuntos em geral também foi indicada por $47 \%$ dos estudantes. Vê-se que aspectos como tratar de assuntos acadêmicos (53\%) possui uma indicação média e quando se trata de assuntos profissionais a recorrência cai consideravelmente (27\%). O que indica uma contraposição interessante: embora a maioria dos estudantes reconheça o potencial das redes sociais como meio de obter informações, boa parte deles ainda não aproveita de forma plena esse potencial para fins acadêmicos e/ou profissionais.

A participação, especialmente ligada à interação também foi verificada a partir do diagnóstico: perguntou-se aos estudantes quais ações costumam praticar ao participar de uma rede, grupo ou comunidade online. O Gráfico 5 mostra as ações mais indicadas pelos estudantes.

\section{Gráfico 5 - Ações praticadas ao participar de uma rede, grupo ou comunidade online}




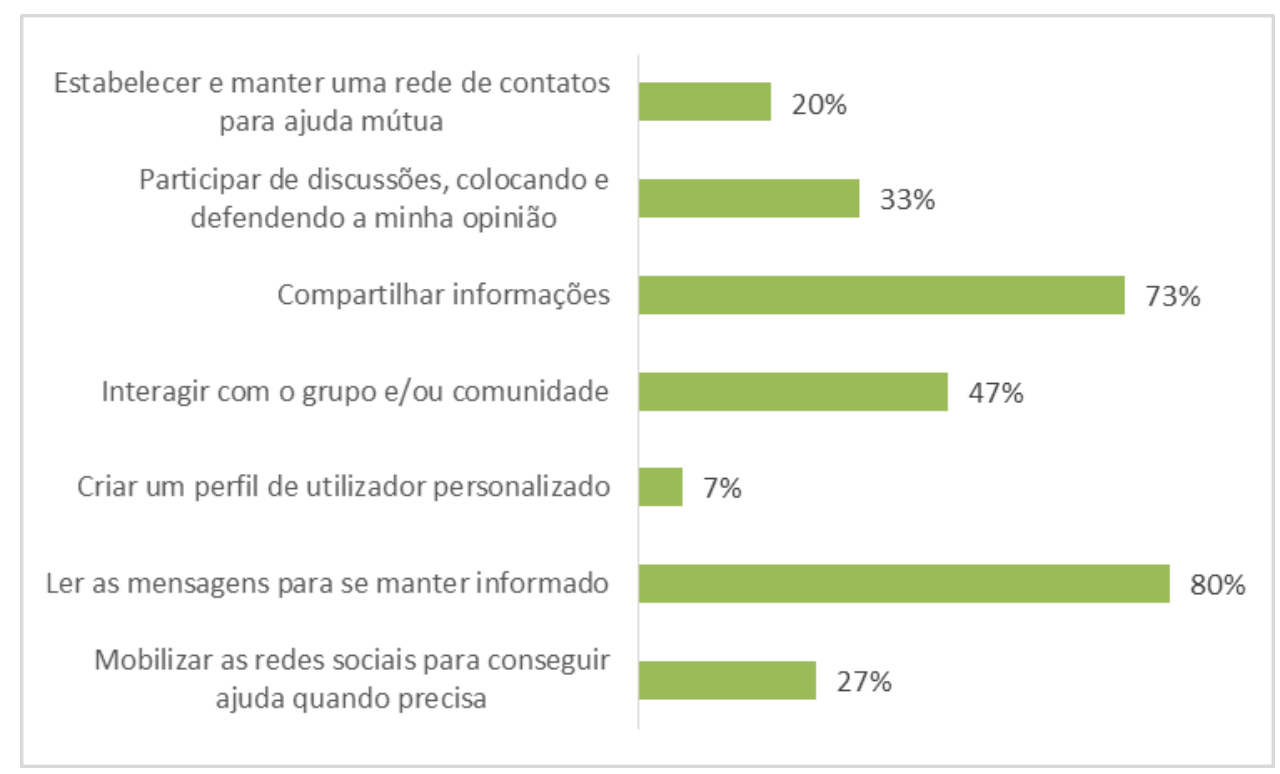

Fonte: Elaborado a partir dos dados da pesquisa (2019).

O que se observa é que a participação dos estudantes em redes, grupos e comunidades virtuais estão mais focalizadas em ler as mensagens para se manter informado e compartilhar informações. Mais uma vez verifica-se que tais ambientes são vistos pelos estudantes como meio para obter $\mathrm{e}$ compartilhar informações, embora seja um mecanismo de informação que exige a interatividade. Apenas $47 \%$ dos estudantes afirmam interagir com os membros do grupo e/ou comunidade. Além disso, outros aspectos que pressupõem o fator interatividade também têm baixa incidência, como: mobilizar as redes sociais para conseguir ajuda quando precisa (27\%), participar de discussões, colocando e defendendo opiniões (33\%) e estabelecer e manter uma rede de contatos para ajuda mútua (20\%).

Ressalta-se que a participação na cultura digital depende da capacidade de interagir dentro de grupos. A colaboração ou trabalho em equipe e flexibilidade e adaptabilidade são exemplos de habilidades que pertencem à referida categoria (OCDE, 2010). Por essa razão, defende-se que a simples participação em redes sociais e ambientes colaborativos não é suficiente, é necessário engajamento e interação baseada no diálogo para que se possa participar ativamente dessa cultura digital.

Ressalta-se que a interação, além de possibilitar o desenvolvimento de laços sociais também contribui para que os estudantes possam atuar 
colaborativamente, quarta categoria a ser analisada no segundo grupo de competências. Com relação ao trabalho colaborativo em rede, os estudantes foram questionados sobre como lidam ao trabalhar em equipe na construção de determinado conteúdo e/ou produto, conforme demonstra o Gráfico 6.

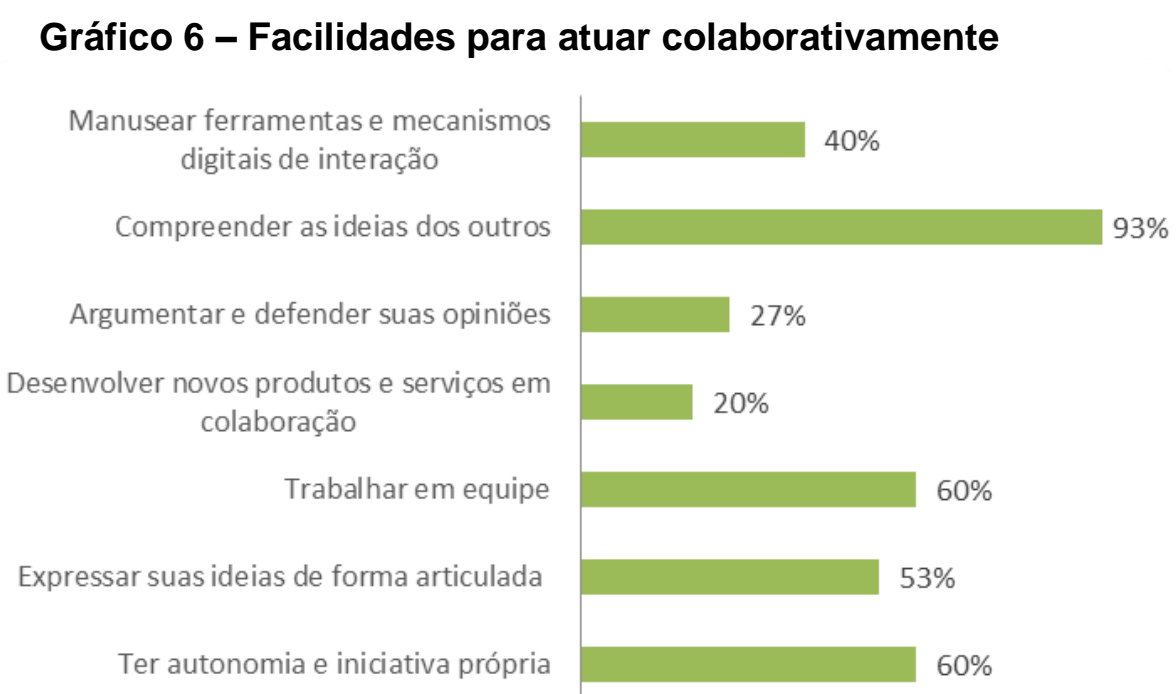

Fonte: Elaborado a partir dos dados da pesquisa (2019).

Sessenta por cento dos estudantes afirmam que se comprometem ao realizar um trabalho colaborativo e entendem sua responsabilidade para 0 sucesso do projeto coletivo. Em torno de $33 \%$ dizem que se comprometem mais do que têm condições de fazer e apenas $7 \%$ costumam assumir uma atitude de liderança. $O$ que indica que, de uma forma geral, os estudantes não encontram dificuldades em trabalhar de forma colaborativa, embora a maioria apenas procure cumprir seu papel no grupo e não costume ir além disso e assumir uma posição de liderança no grupo.

Ainda sob esse aspecto da colaboração, os estudantes foram questionados sobre quais ações consideram mais fáceis ao atuar colaborativamente. De acordo com os dados ilustrados no Gráfico 6, pode-se observar que dentre as ações mais fáceis estão: compreender as ideias dos outros $(93 \%)$, trabalhar em equipe $(60 \%)$ e ter autonomia e iniciativa própria (60\%). Embora os estudantes considerem uma tarefa fácil trabalhar em equipe e lidar com outros sujeitos, verifica-se que o desenvolvimento de produtos (20\%) é visto como uma tarefa mais complexa que as demais, assim como 
argumentar e defender opiniões (27\%).

A produção colaborativa é entendida, neste trabalho, como parte de um processo criativo e coletivo, no qual a criação de conteúdo ocorre de maneira interativa. Tal processo envolve o trabalho em colaboração, especialmente via rede; a autonomia, a iniciativa e também o respeito ao outro são o centro do modelo da comunicação; como diz Wolton (2010, p.65): "aceitar a identidade e organizar a convivência das diferenças".

O Gráfico 7 traz dados acerca da última categoria a ser analisada no grupo do comportamento comunicacional, a avaliação da comunicação. Neste quesito, propôs-se aos estudantes pensarem sobre seus próprios conhecimentos, habilidades e atitudes no processo comunicativo. Assim, os mesmos definiram quais ações consideram mais fáceis de serem realizadas.

Considera-se a autoavaliação um aspecto transversal que envolve todo o comportamento estudado neste trabalho. O seu objetivo é levar o sujeito a pensar sobre seu comportamento e levá-lo a compreender melhor o seu próprio processo de desenvolvimento, tornando-se mais autônomo e independente nesse processo.

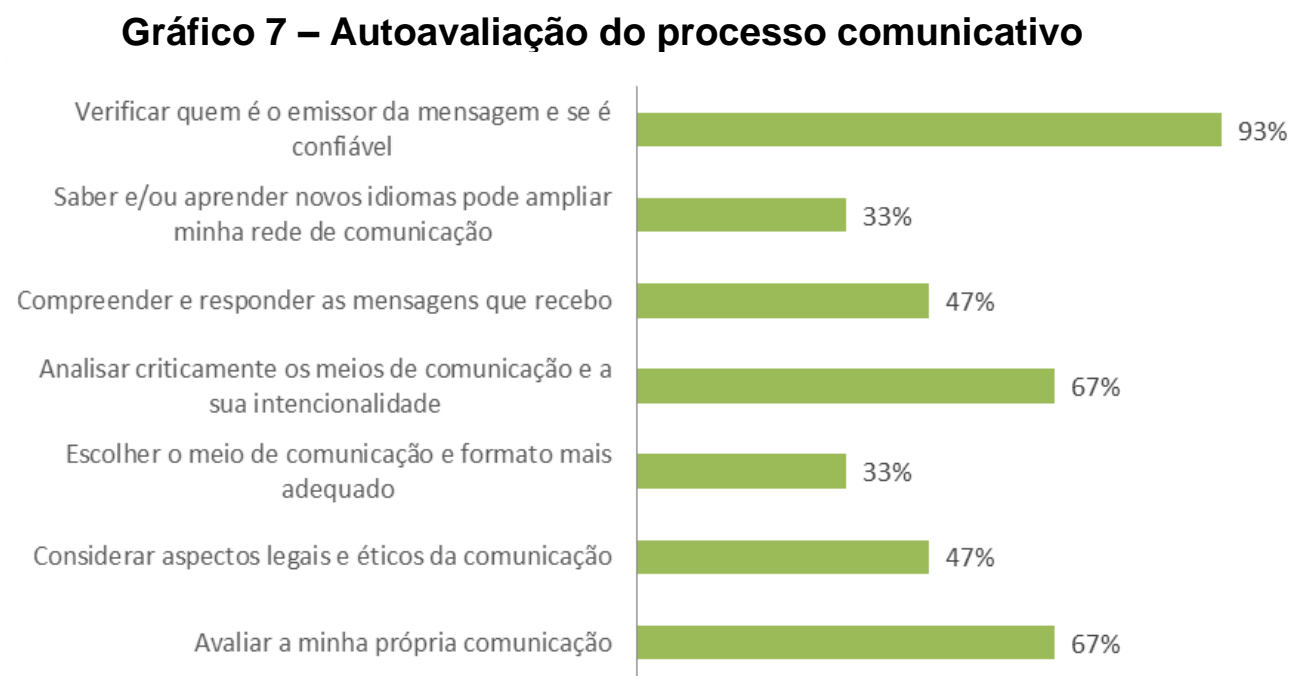

Fonte: Elaborado a partir dos dados da pesquisa (2019).

Nesse sentido, observa-se que para os estudantes verificar quem é o emissor da mensagem e se este é confiável (93\%), analisar criticamente os meios de comunicação e sua intencionalidade (67\%) e avaliar a própria 
comunicação (67\%) são as ações apontadas como de maior facilidade. Tais aspectos apontados indicam que há uma consciência crítica por parte do grupo e uma preocupação em torno do seu próprio comportamento comunicacional. Farias (2016) considera relevante que o sujeito desenvolva uma consciência crítica com foco na responsabilidade individual e coletiva para estabelecer-se como protagonista, ou seja tornar-se ator principal do seu próprio aprendizado.

Já as opções saber e/ou aprender novos idiomas e escolher o meio de comunicação e formato mais adequado são menos indicadas pelos estudantes, tendo apenas $33 \%$ da totalidade. Destacam-se, ainda, outras alternativas indicadas pelos estudantes: compreender e responder as mensagens (47\%); e considerar os aspectos legais e éticos da comunicação (47\%). Aspectos como a linguagem, o canal de comunicação e os aspectos éticos da comunicação precisam ser pontos de reflexão constante, pois envolvem a preocupação com o outro, característica central do agir comunicativo. Como diz Wolton (2006, p. 175): "Comunicar não é apenas produzir e distribuir informação, é também ser sensível às condições nas quais o receptor a recebe, aceita, recusa, remodela em função das suas escolhas filosóficas, políticas, culturais. "

\section{CONCLUSÕES}

Esta pesquisa estudou o comportamento infocomunicacional de um grupo como diagnóstico necessário antes de ofertar um curso de competências infocomunicacionais. Isso foi possível a partir da identificação do comportamento desses sujeitos em relação à informação e à comunicação: como percebem uma necessidade informacional, como buscam fontes e avaliam informações, com a finalidade de usá-la e, também, de que maneira estabelecem comunicação, compartilham conteúdos, desenvolvem laços sociais, atuam colaborativamente e avaliam a comunicação.

Nesta direção, foi possível perceber que em relação ao comportamento informacional, os sujeitos investigados buscam informações sobre temas gerais para sanar necessidades corriqueiras, prioritariamente na internet, usando os buscadores ou motores de busca para esse fim. Também utilizam estratégias 
como: pesquisar informação em diversas fontes com o intuito de confrontá-las, avaliar a atualização e o contexto para que seja possível identificar manipulação, distinguindo, sobretudo, se se trata de um fato ou de uma opinião.

No que se refere ao comportamento comunicacional, os dados demonstraram que os estudantes consideram principalmente aplicativos de mensagens instantâneas como ferramentas de comunicação eficaz. Ainda nesta direção, demonstram preocupação com a confiabilidade da informação que compartilham nesses ambientes, relendo-as antes de enviar e considerando o potencial interesse dos destinatários. Utilizam também as redes sociais para se manter informados e compartilham conteúdos. Contudo, há uma certa inibição quando se aventa a questão da interação efetiva nesses espaços. Acenam que consideram um alto nível de facilidade no contexto da atuação em colaboração, especialmente no que diz respeito à compreensão das ideias do outro, o trabalho em equipe, a inciativa e a autonomia.

Ante o exposto, destaca-se que esses dados ajudaram na customização do curso, trazendo um ambiente de aprendizagem onde fosse possível desenvolver atividades que contemplassem situações de uso informacional no ambiente onde esses alunos estão a maior parte do tempo, notadamente na web. Além disso, foi possível redimensionar as estratégias de comunicação com o grupo de estudantes, já que se adotou inicialmente o uso de chat no próprio ambiente virtual de aprendizagem (Moodle) para esse fim, contudo, esse diagnóstico demostrou que seria mais eficaz o uso do whatsapp, o que se confirmou ao longo do desenvolvimento do curso.

Torna-se evidente, portanto, que para promover um curso desta natureza se faz necessário conhecer o comportamento infocomunicacional dos sujeitos que o cursarão, tendo em vista a possibilidade de adequação de métodos, técnicas, conteúdos e avaliações à realidade de aprendizagem dos envolvidos, além de basear-se no conhecimento prévio dos sujeitos.

Oportunamente, ressalta-se que esse estudo não pretende ser conclusivo, mas trazer à tona a necessidade de se conhecer o comportamento infocomunicacional dos sujeitos em um processo de aprendizagem, onde seja 
possível uma avaliação contínua do processo. Assim, considera os atores partícipes do curso (estudantes de Biblioteconomia e Arquivologia da UFBA) como parte fundamental desse processo.

\section{REFERÊNCIAS}

BARRETO, Aldo de Albuquerque. Mediações digitais. DataGramaZero Revista de Ciência da Informação, João Pessoa, v.10, n.4, 2009.

BERRÍO-ZAPATA, Cristian et al. El paradigma de Comportamiento Informacional como alternativa para comprender los fenómenos informacionales en América Latina. Revista Interamericana de Bibliotecología, v. 39, n. 2, p. 133-147, 2016.

BORGES, Jussara; BRANDÃO, Gleise. Evolução contexto-conceitual das competências infocomunicacionais. Logeion Filosofia da Informação, v. 3, p. 75-86, 2017.

BORGES, Jussara. Competências infocomunicacionais: estrutura conceitual e indicadores de avaliação. Informação \& Sociedade (UFPB. ONLINE), v. 28, p. 123-140, 2018.

BRANDÃO, Gleise. LIMA, Jussara. Emprego da competência em informação por estudantes de arquivologia da Universidade Federal da Bahia. Agora (Florianopolis), v. 24, p. 277-310, 2014.

BRANDÃO, Gleise. LIMA, Jussara. A contribuição das competências infocomunicacionais na atuação do arquivista enquanto mediador. Em Questão, Porto Alegre, v. 24, n. 3, p. 38-67, set./dez. 2018.

COMITÉ GESTOR DA INTERNET NO BRASIL. Pesquisa sobre o uso das tecnologias de informação e comunicação nos domicílios brasileiros: TIC domicílios 2018 [livro eletrônico]. São Paulo: Núcleo de Informação e Coordenação do Ponto BR, 2019.

FARIAS, Maria Giovanna. Mediação e competência em informação: proposições para a construção de um perfil de bibliotecário protagonista. R. Ci. Inf. e Doc., Ribeirão Preto, v. 6, n. 2, p. 106-125, set. 2015/fev. 2016.

FURTADO, Renata Lira; ALCARÁ, Adriana Rosecler. Modelos de comportamento informacional: uma análise de suas características. In: Seminário científico de Arquivologia e Biblioteconomia-do outro lado da informação, 2015, Marília. Anais [...]. Marília: Unesp, 2015, p. 1-10. 
GASQUE, Kelley Cristine. COSTA, Sely Maria. Evolução teórico-metodológica dos estudos de comportamento informacional de usuários. Ci. Inf., Brasília, DF, v. 39 n. 1, p.21-32, jan./abr., 2010.

OCDE. Habilidades y competencias del siglo XXI para los aprendices del neuvo milenio en los países de la OCDE. España. Ministerio de Educación, Cultura y Deporte. Instituto de Tecnologías Educativas. 2006. Disponível em: http://recursostic.educacion.es/blogs/europa/media/blogs/europa/informes/Habil idades_y_competencias_siglo21_OCDE.pdf. Acesso em: 08 jun 2020.

OTTONICAR, Selma Leticia Capinzaiki; BASSETTO, Clemilton Luis; DO NASCIMENTO, Natália Marinho. O comportamento informacional e a competência em informação: uma abordagem para geração de inovação em micro e pequenas empresas. Encontros Bibli: revista eletrônica de biblioteconomia e ciência da informação, v. 23, n. 52, p. 18-33, 2018.

PASSARELLI, Brasilina et al. Identidade conceitual e cruzamentos disciplinares. In: PASSARELLI, Brasilina; SILVA, Armando M.; RAMOS Fernando (Orgs.). E-infocomunicação: estratégias e aplicações. São Paulo: Senac São Paulo, 2014

SANTOS, Jaires Oliveira; BARREIRA, Maria Isabel de Jesus Sousa. O bibliotecário do Nordeste Brasileiro: elucubrações do processo de aprendizagem e da competência em informação. RBBD. Revista Brasileira de Biblioteconomia e Documentação, v. 15, n. 2, p. 237-250, 2019.

SANTOS, Jaires Oliveira. Competência em Informação dos egressos do curso de Biblioteconomia: uma análise na região Nordeste do Brasil. 2015. 142f. Dissertação (Mestrado em Ciência da Informação) - Instituto de Ciência da Informação, Universidade Federal da Bahia, Salvador, 2015.

SILVEIRA, Martha. ODDONE, Nanci. Necessidades e comportamento informacional: conceituação e modelos. Ci. Inf., Brasília, v. 36, n. 2, p. 118-127, maio/ago. 2007.

SHENTON, Andrew K.; HAY-GIBSON, Naomi V. Information behaviour and information literacy: The ultimate in transdisciplinary phenomena?. Journal of Librarianship and Information Science, v. 43, n. 3, p. 166-175, 2011.

TUOMINEN, Kimmo; SAVOLAINEN, Reijo; TALJA, Sanna. Information literacy as a sociotechnical practice. The Library Quarterly, v. 75, n. 3, p. 329-345, 2005.

WILSON, Thomas. Human Information Behavior. Informing Science, v.3, n. 2, 2000. Disponível em: http://www.inform.nu/Articles/Vol3/v3n2p49-56.pdf . Acesso em: 03 jun 2020.

WOLTON, Dominique. É preciso salvar a comunicação. Casal de Cambra: Caleidoscópio, 2006. 
WOLTON, Dominique. Informar não é comunicar. Porto Alegre: Sulina, 2010.

\title{
INFOCOMMUNICATION BEHAVIOR: A DIAGNOSIS BETWEEN STUDENTS FOR THE PROMOTION OF INFOCOMMUNICATION COMPETENCES
}

\begin{abstract}
Introduction: Infocommunicational behavior reflects the way people relate to content (information) and to other people (communication). Objective: In this article, we intend to know the infocommunicational behavior of a group as a necessary diagnostic before offering a course of infocommunicational competences. Methodology: In this sense, the quantitative-qualitative approach is adopted, with a view to quantifying the data, but also offering qualitative interpretations and inferences. The data collection was based on the application of a questionnaire, answered by 15 students of Archivology and Librarianship about their behavior towards information and communication. Therefore, it is the perception of the students themselves from questions of multiple choice. Results: The results indicated that the subjects investigated seek information on general topics to address common needs, using search strategies, confront and evaluate information, especially regarding the update and context so that it is possible to identify manipulation, distinguishing, above all, facts of opinion. In the communicational aspect, they use instant messaging and e-mail applications as communication tools as well as social networks to keep informed and share content. They are concerned with the reliability of the information, but they have limitations related to the effective interaction in these spaces. Conclusions: It is concluded that the delineation of an approximate profile to infocommunicational behavior contributes to the development of actions and strategies that favor the promotion of infocommunicational competences.
\end{abstract}

Descriptors: Infocommunicational behavior. Information behavior. Communication behavior. Infocommunication literacy.

\section{COMPORTAMIENTO INFOCOMUNICACIONAL: UN DIAGNÓSTICO ENTRE ESTUDIANTES PARA LA PROMOCIÓN DE HABILIDADES INFOCOMUNICACIONALES}

\begin{abstract}
RESUMEN:
Introducción: el comportamiento de comunicación informativa refleja la forma en que las personas se relacionan con el contenido (información) y con otras personas (comunicación). Objetivo: Este artículo tiene como objetivo conocer el comportamiento de comunicación de un grupo como diagnóstico necesario antes de ofrecer un curso de competencias de comunicación. Metodología: en este sentido, se adopta el enfoque cuantitativo y cualitativo, desde la perspectiva de cuantificar los datos, pero también ofrece interpretaciones e inferencias cualitativas. Los datos se recopilaron mediante la aplicación de un cuestionario, respondido por 15 estudiantes
\end{abstract}


de Archivología y Biblioteconomía sobre su comportamiento con respecto a la información y la comunicación. Por lo tanto, es la percepción de los propios estudiantes de las preguntas de opción múltiple. Resultados: Los resultados indicaron que los sujetos investigados buscan información sobre temas generales para resolver necesidades comunes, utilizando estrategias de búsqueda, confrontar y evaluar la información, especialmente con respecto a la actualización y el contexto para que sea posible identificar la manipulación, distinguiendo, sobre todo, hechos de opiniones En el aspecto de la comunicación, utilizan la mensajería instantánea y las aplicaciones de correo electrónico como herramientas de comunicación y también las redes sociales para mantenerse informados y compartir contenido. Les preocupa la fiabilidad de la información, pero tienen limitaciones relacionadas con la interacción efectiva en estos espacios. Conclusiones: Se concluye que el diseño de un perfil de infocomunicación es crucial para el éxito de las acciones y estrategias que promueven la promoción de competencias de infocomunicación.

Descriptores: Comportamiento informacional. Comportamiento informacional. Comportamiento comunicativo. Alfabetización en infocomunicación.

Recebido em: 21.11.2019

Aceito em: 02.06.2020 